\title{
Filling in the Blank
}

\section{Divya Pradhan}

\begin{abstract}
Minority communities tends to draw a blank in the national imagination. The paper explores the problems of identity crisis and the use of translation to mitigate it. A translated text like Gorkha's Imagined: I.B.Rai in Translation, becomes a means of communicating with the 'Other' through literature the visibility of the Nepali community of India and thereby placing it as an integral part of the Indian nation. For the unrecognized minority, narrating becomes of fundamental importance. Translation and communication of minority texts is instrumental in restructuring the asymmetrical power relations among nations in India.
\end{abstract}

Agha Shahid Ali wrote a poignant poem called, "Country without a post office". The poem talks about the angst faced by Kashmiris during the political turmoil in Kashmir in the 1990s. A seemingly innocuous effect was that, mountains of mail remained undelivered. One may ask here how the absence or the presence of a functioning post office is related to pain. The post office is an important metaphor in the life of the marginalized communities. It represents permanence, fixity of identity and also a legitimacy of the identity it symbolizes. One cannot concoct addresses and pin codes and hope that the letters will be delivered. The system works only if the your address and home are acknowledged by the others to be yours. And that there is consensus that you as an entity live there and your existence there is rightfully recognised. As nations within India the minority communities share this lack of a Post Office.

For minority communities this Absence of their Presence is what gives rise to feelings of insecurity, alienation and dislocation. In literature and politics these feelings have manifested itself into 
a major theme - Alienation. This position has arisen from a distinct historical, social, political context and must be understood within that very context and not within a broad pan-Indian nationalistic discourse.

It is within this framework that I will be reading Gorkha's Imagined: I.B.Rai in Translation, (2009) as my entry point to substantiate my position. I.B Rai is one of the leading writer, critic, philosopher and academician among the Indian Nepalis. This translated text is a collection of short stories and essays. About the collection the editor Prem Poddar writes, "The mixing and merging of ambivalent ethno-national narratives is central to his articulation....which are collected and translated here provide an insightful albeit not definitive, sense of his preoccupation with our 'troubled' time." (Poddar 13).

The most important issue that the Nepali community has had to deal with is the issue of identity. "Caught in the spaces between Nepal, Darjeeling, Sikkim, Bhutan, North-Eastern India, Burma, and the various theatres of war around the world, Rai's characters dramatise the in-betweenness of longing and belonging".(Poddar 18). Historically Darjeeling district and its contiguous areas were always inhabited by the Nepali Community. 68 years post independence Nepali community in India has been facing varying degrees of alienation. This alienation by and large arises out of the glaring absence in the National Imagination which translates into an absence also in terms of social, political, economic and developmental issues. As I. B. Rai writes in 'Indian Nepali Nationalism and Nepali Poetry', "As a result of uneven development in the country, some units if the Indian nation have fallen behind the others, and these facts, together with the attendant feelings, have to be reflected in their literature. And one has to admit the possibility of their being as many manifestations of nationalism as there are stages of societal development." (Poddar 173) From the year 1907 under the leadership of Hill Men Association there has been a demand for a separate administrative unit from the rest of Bengal. Time and again the demand for a 
separate state has been raised. This issue is primarily seen as a solution to the "identity crises" faced by the Nepali community. Very often they are erroneously thought to belong to Nepal a country with which Darjeeling district shares its borders and a country with which the Nepali community of India share cultural and linguistic affinity. (Incidentally this crisis is also faced by the madhesias of Nepal who share cultural and linguistic affinity with the Indians living across the border.) This confusion arises from the tendency to confuse between ethnicity and citizenship. This is the historical context in which the text Gorkhas Imagined has to be studied.

The vacuity created due to the identity crisis and the use of translation as a tool to fill this blank is the main concern of this paper. Here the Blank which has to be filled, is present in what I would like to call the National Imagination. I use the term National Imagination to denote the Indian mindscape. It is the mindscape of the majority, the mainstream, those who occupy the center that is India, those whose voices count. By equating the national with the mainstream I am not excluding the marginal, the minority from the national. But most of the marginal voices have remained but blanks and gaps that are continuously overlooked, potholes in the Indian nation, whose presence is jarring, as they impinge upon the national imagination as death counts, strikes and political unrest in newspaper reports.

Deriving from Michel Foucault's notion that any regime of normalcy engenders exclusion, Poddar says, "In similar fashion, the category 'Indian citizen' presupposes the category 'nonIndian citizen', and in the discourses of modernity the former is assigned a positive connotation at the expense of the latter. The same is true of a discursive opposition that sets up terms such as 'non-Bengali' or 'non-domicile', or even 'non-Gorkha'. 'non-Nepali'. The intellectual challenge would be to interrogate how the oppositional term has been produced historically and further to explain how power is distributed in constituting and reproducing the opposition. The matrix of the'national' here is over determined 
as the 'Nepali' or 'Gorkha' seeks to locate and relocate.' (21-22)

The translated text, a collection of short stories and critical essays is used as a means of communicating with the 'Other' through literature the visibility of the Nepali community of India and thereby placing it as an integral part of the Indian nation. For the unrecognized minority, narrating becomes of fundamental importance. Translation and communication of minority texts is instrumental in restructuring the asymmetrical power relations among nations in India. Here (re)claiming becomes very important and the translator/writer is as important as the political activist.

"Etymologically speaking, the word translation comes from the Latin translatus, 'carried over', serving as past participle of transferre, 'to bring over, carry over, from trans+latus, 'borne, carried', from tlatos."(Poddar 13-14) Poddar further says that in the translation process salvaging remains at the core and that there is no nostalgia for the lost original but rather a gesture towards an afterlife. It must also be remembered that " Translation is not an innocent, transparent activity but is highly charged with significance at every stage; it rarely, if ever, involves a relationship of equality between texts, authors or systems." (Bassnett \&Trivedi 2)

Translation has been likened to archeology in its ability to retell, rewrite and thus communicate. I will therefore be looking at translation as a tool for the much needed communication with the 'Other' and how it simultaneously also becomes a tool for intervention in the ongoing political demand for a separate state.

The stories which have been translated are one of the finest works in Nepali literature. Most of them are written in the realistic mode and depict the lives and times of the Nepalis. Displacement, dislocation, deprivation are some of the general themes. Some stories like "Jarr" are culture specific and one needs to understand the social practices of the community. I will not be dealing with the stories per se as the paper focuses on the theoretical underpinnings of the act of translation among the marginalized. " 
A sensitive texturing of the voice of the other, whoever the other maybe, in a performative ( as opposed to a pedagogical) English translation of a Nepali text would re-imagine and rewrite a more inclusive nation"(Poddar 25).

Octavio Paz claims that translation is the principal means we have of understanding the world we live in.( Bassnett \&Trivedi 3). Translation as a tool of cultural exchange has been around since time immemorial. So has the study of the linguistic process of translation. However the communicative and sociocultural approach to translation was developed by José Lambert, André Lefevere, Susan Bassnett etc. Over the last three decades the influence of post colonialism and post modernism has made translation studies more complex. Influential theorists like Andre Lefevre, Susan Basnett, Tejaswini Niranjana and others have mainly dealt with translations where the focus remains issues related to representation by and for the West in translated texts.

In the Indian universities where courses are being offered in Translation Studies, texts that form a part of the syllabi are texts belonging to the mainstream cultures - Tagore, O.V. Vijayan, Sadat Hassan Manto, Premchand and Ismat Chugtai. Just as the minority is absent from the Indian imagination its literature is also absent in the field of translation studies. "If contemporary cultural theory has questioned notions of identity and belonging in the recently decolonised areas of the globe, it has also identified the need to raise similar questions in areas conventionally located in the metropolitan centre, as well as to examine the prevalence of what has been called internal colonialism within a decolonised state. Internal colonialism is an issue that needs to be thrashed out well beyond the rubric of politics of identity, more is required than ethnic self assertion alone". (Poddar 20)

It was once assumed that the original text is, "de facto superior to the translation, which was relegated to the position of being merely a copy, albeit in another language". (Basnett \& Trivedi 2) But now the translated text is being seen as an entity in itself and not necessarily subservient to the "Original". In this 
context Harish Trivedi talks about the impossibility of applying western notion of faithfulness to a text like Ramayana. The numerous versions of Ramayana, "clearly and substantially based on the Sanskrit original, it repeats or retells, but with sufficient indisputable originality for it to be regarded by everyone as an autonomous freestanding creative work of the first order" (Bassnett \&Trivedi 9-10).

With the translated text no longer being seen as inferior to the source text, it acquires a degree of legitimacy and can act as a free agent. Translation is not simply a creative exercise unlike other works of literature. It arises out of a certain need, and the intent behind its process becomes very important. Quoting Peter Hitchcock, Dialogics of the Oppressed Poddar writes that translation can " either ...domesticate the foreign text or otherwise ... ameliorate its disruptive potential'...while also raising the prospect of transnational narratives or articulations which might recognise and even celebrate- the multiple and different voices within and across communities"( 24-25)

In Nation, Language and the Ethics of Translation, Sandra Berman writes, "There has probably never been a time when issues of nation, language, and translation have been more important or more troubling than they are today. In a world where individual nation-states are increasingly enmeshed in financial and information networks, where multiple linguistic and national identities can inhabit a single state's borders or exceed them in vast Diasporas, where globalization has its serious-and often violent- discontents, and where terrorism and war transform distrust into destruction, language and translation play central, if often unacknowledged, roles." (Berman 1)

The nation-state as it stands today is a site of contestation for social, political, cultural and economic control. The world remains deeply fragmented in terms of ethnicity and race. The global village remains an ideal at best. Translation as a medium thus helps to bridge these gaps and divides. To signify the importance of translation, Ilan Stavans writes that modernity is not lived 
through nationality but through translationality. Sandra Berman further writes, "Only a more deeply nuanced understanding of these linguistic ligatures, and a heightened awareness of their relationship to the national as well as to the "postnational," and "subnational," can begin to parse the painful dialectics of local and global, past and present, that cross the contemporary world. ... and urge, in the process, a very different, more reflective, and more culturally variegated "global consciousness."(Berman 2)

Translation no longer remains a simply a literary tool. It is cultural, social and political and must be understood as thus. Language has become a very powerful tool in the assertion of identities. Ngugi Wa Thiongo gave up writing in English as a first step towards the decolonizing process and began writing exclusively in Kikuyu. However for most marginalized community such an extreme act will only lead to further exclusiveness when the call of the hour is inclusiveness, even if you have to impinge yourself on the national imagination. "Homi Bhabha, a multiplydisplaced theorist, foregrounds the transnational-translational nature of our times: the time for "'assimilating' minorities to holistic and organic notions of cultural value has dramatically passed", he upbraids us, and insists that the , "very language of cultural community needs to be rethought".(Poddar 20). English no longer remains the language of the colonizers. But in fact has become an important linguistic tool in the asymmetrical power relations between national and regional languages. So in such a case, criticisms which center on the use of English and not a bhasa language when only a certain percentage of the population speak English doesn't really hold much ground, primarily because of the impossibility and also the political unfeasibility of making any other language a link language.

What the text Gorkhas Imagined seeks to do is to reclaim a space for itself in the national imagination. One needs to look at both these term Gorkhas and Imagined. Gorkhas refer to the Nepali community of India, Imagined here could be seen either in terms of the Nepali nation as being imagined, along the lines 
of Benedict Anderson's thesis of the nation as an imagined community or the need for the Indian nation to itself start imagining the Nepali community which has hitherto been just a blank. It is the 'Other' who has to imagine the Nepali community, as mediated by the translated text.

In his essay Indian Nepali Nationalism and Nepali Poetry I.B. Rai writes,"...to correct a misconception that still persists and which is rather deliberately fostered regarding the genesis of Indian Nepalis. Those who claim to be delvers into the past and yet describe Indian Nepalis as 'settlers' or 'immigrants' betray their blatant ignorance of the history of this region. After the AngloNepalese War, through the Treaty of Sagauli of 1816, Nepal was made to cede lakhs of square miles of Nepalese territory to the British East India Company, together with the Nepali people living thereon. These were the forefathers of today's Indian Nepalis."(Poddar 173-174)

In the year 2006 Laura Bush launched the "Global Cultural Initiatives" to enhance and expand America's cultural diplomacy. The first phase of the programme was to, "sponsor, translation and publications, thus affording Americans and readers in other nations access to the best of each other's literature." (Flowtow 189). Here we see how translation as a practice is being used as a complement and to give legitimacy to political action. Gorkhas Imagined as a translated text occupies a similar position wherein the text becomes an integral part of the ongoing political movement for a separate state. Translators translating texts from the margins shoulder a lot of responsibility. The contemporary world with its competing interests calls for engagements at several levels from both the mainstream and the minorities. Exclusiveness only engenders alienation and violence. Translation as a unit of culture becomes a potent tool of communication in the Babel of human languages. Other units of culture like handicrafts and handloom products only perform the role of exoticizing the minority, it does not bridge gaps. Translated texts as acts of intervention are more real and powerful and fundamental in cultural diplomacy. 
As Prem Poddar aptly sums up, "As I see it, Rai's reflections on the Nepali language, the Gorkha/Nepali language, the Gorkha/ Nepali community and his own writing practice can be read in two ways. The first is in terms of telos: that writing will strengthen the nation or ethnie. The other way is the more troubled interrogative reading, that raises the same question of cultural identity, through textual elisions and ambivalences inter alia, about writing and the Gorkha/Nepali community... We await the arrival of such a translation, such a liberating history, a futuricity, a place where the received and assertive vocabulary of cultural community is recast. for now, we welcome the present collectanea of translations of Rai's shorter works as a step in that direction." (36-37)

\section{REFERENCE}

Bassnet, Susan \& Trivedi, Harish. Post-Colonial Translation: Theory \& Practice. London: Routledge. 1999.

Berman, Sandra. "Introduction" Nation ,Language and the Ethics of Translation. ed. Sandra Berman \& Michael Wood. New Jersey: Princeton University Press. 2005.

Flowtow, Luise von. Revealing the 'soul of which nation?': Translated literature as cultural diplomacy. In TranslationReflection, Refraction and Transformations. ed. Prafulla C Kar and Paul St-Pierre Philadelphia: John Benjamin Publishing Company. 2007.

Prasad, Anmole \& Prem Poddar. Gorkhas Imagined: Indra Bahadur Rai in Translation. Kalimpong: Mukti Prakashan.2008. 